\title{
Smart brush tool now software integrated
}
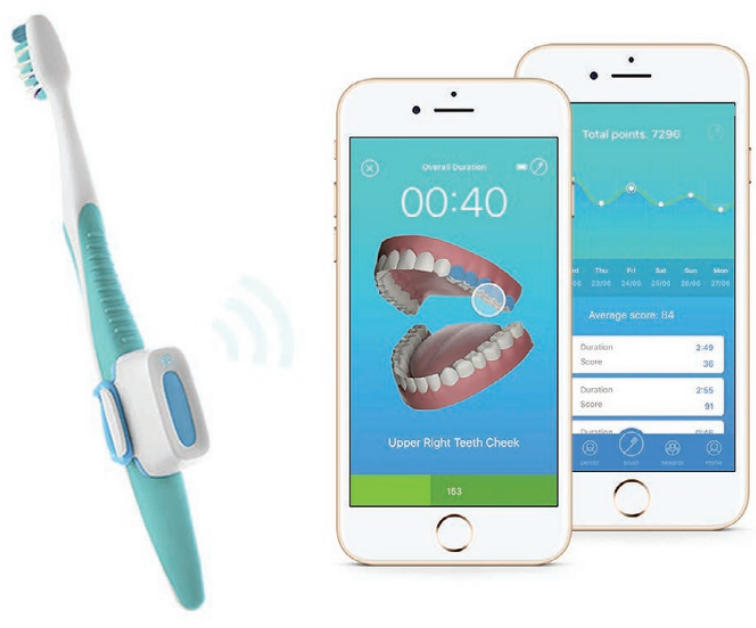

The oral hygiene product Brushlink has been integrated into dental practice management system Software of Excellence (SOE), making it easier for dental professionals to access their patients' data from Brushlink.

\section{A super-duper autoclave}

Prestige Medical, worldwide decontamination product specialist, has launched its state-of-the-art autoclave, Advance Pro.

The Blackburn, Lancashire-based company, an expert in the development and manufacture of sterilisation equipment, has now added Advance Pro to its extensive portfolio, which also includes the Anima, Visage, PodiaClave+ and Classic range of autoclaves.

The new Advance Pro features the innovative FlexiRack system; a first within the industry, this unique aluminium rack can support 12 individual rails and can be arranged into 20 different configurations.

Another highlight of FlexiRack is the ground-breaking Heat Transfer System, designed and developed to take full advantage of the high performance thermal conductivity properties of aluminium.

The class B steriliser, which includes non-vacuum cycles for maximum flexibility, is available with either a 16 or 22 litre capacity chamber and its compact style is ideal for worktops where space is limited.
The Brushlink device is a tiny hi-tech Bluetooth unit that attaches easily to any toothbrush and monitors brushing frequency, duration and - for the first time - angulation so that correct brushing angles can be encouraged, reinforced and monitored to help prevent gum disease. It effectively turns any toothbrush into a 'smart brush' at around a tenth of the price of smart brushes currently on the market.

The accompanying free mobile phone app provides the user with real time brushing guidance and performance monitoring. Each brushing session is scored and monitored and the cumulative data can be shared with dental professionals in order to target help and advice. Data can be stored for up to three months, so there is no need for patients to have their phones with them every time they brush.

The news coincides with Brushlink being available to buy on Amazon for the first time - bringing it within easy reach of thousands of new users.

Integration with the SOE system indicates an acceptance of Brushlink within the profession and the ability for dental professionals to access data from their patients' Brushlinks more easily and in tandem with other patient data.

https://brushlink.com/.

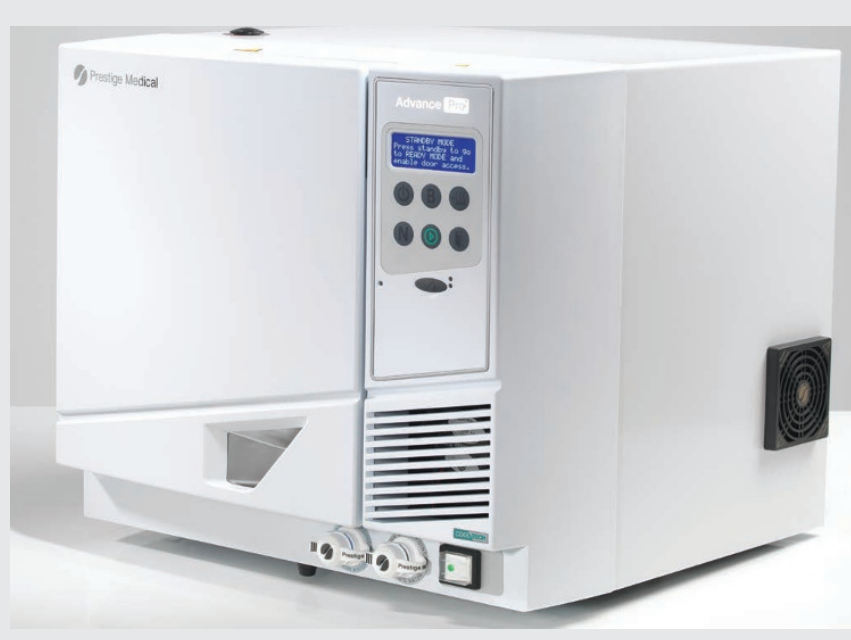

Further enhancements include easy to use push button operation, backlit LCD display and pressure die cast door, with stainless steel reinforced Teflon coating, and easy change gasket system.

For more information on the Advance Pro contact sales@prestigemedical.co.uk or call 01254844103.

\section{Motivate patients with new whitening toothpastes}

With National Smile Month just around the corner, now is a good time to reach out to patients in need of oral health assistance.

Between 14 May and 14 June, the campaign will be running a number of initiatives to educate, motivate and communicate. But the aim of National Smile Month isn't just to improve oral health, but to do so in a fun way that engages on a personal level with the patient.

Curaprox has the perfect solution to help you with this - its new Be You range of whitening toothpastes. Available in six unique, inviting flavours and colours including tangy Grapefruit with
Bergamot, Watermelon and Gin and Tonic with Persimmon, the range is designed to motivate patients into taking a personal, more playful approach to their oral health routine. All while ensuring that patients achieve lasting fresh breath, natural saliva support, effective whitening and protection against decay.

Do your bit for National Smith Month and recommend the Curaprox Be You range.

For more information call 01480 862084, email info@curaprox.co.uk or visitwww.curaprox.co.uk. 